Dept. of Poultry Diseases, Faculty of Vet. Med. , Al-Baath University, Hama, Syria.

\title{
THE ROLE OF BREWER'S YEAST IN THE IMPROVEMENT OF SPECIFIC AND NON- SPECIFIC IMMUNITY IN BROILER CHICKENS IN SYRIA
}

(With 3 Tables and 3 Figures)

By

MONA AL SHARABI and M. FADEL

(Received at 3/4/2010)

دور خميرة البيرة في تحسين المناعة النوعية وغير النوعية في دجاج اللحم في سوريا تحنيا

منحى الشرابي ، محمد فاضل

أجريت الدر اسة على عدد (500) طير اً من إحدى الهجن التجارية لاجاج اللحم، وقد استخدمت

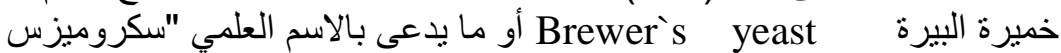

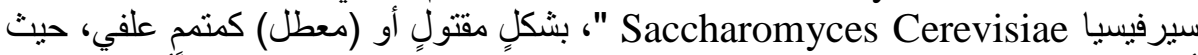

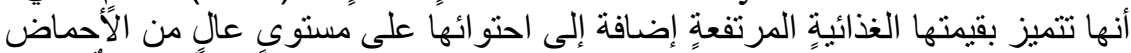

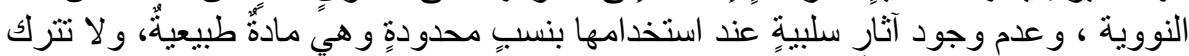

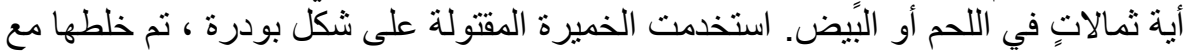

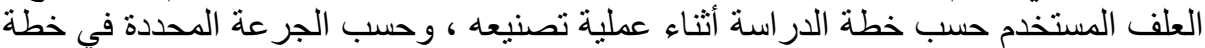

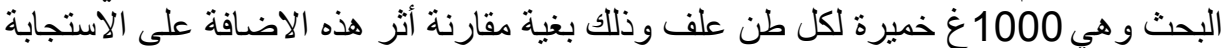

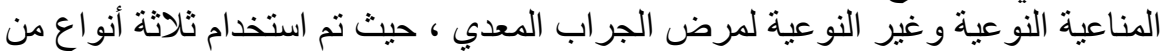

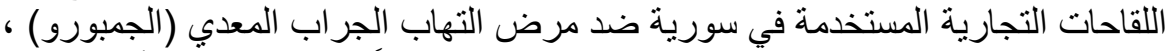

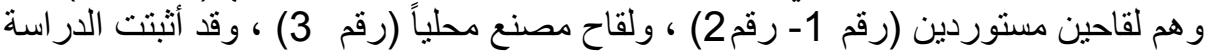

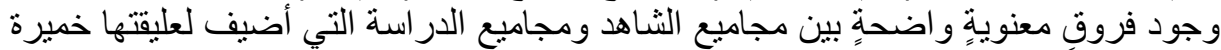

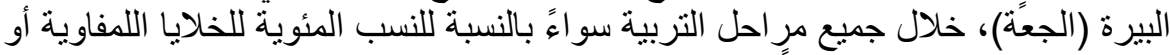

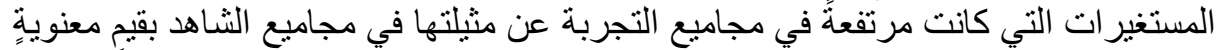

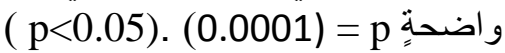

\section{SUMMARY}

The study was conducted on 500 commercial broiler chickens fed on diets supplemented with Brewer`s yeast, (Saccharomyces Cerevisiae) in inactive cells. The Brewer's yeast has a high nutritional value in addition to containing a high level of Nucleotides. There are no negative effects when it is used in a limited rates. It is a natural 
substance and it doesn't leave any residues in meat or eggs. The inactive Yeast was used in the form of powder which was mixed with the feed used during the feed manufacturing process and according to the specified dose, $1000 \mathrm{~g}$ yeast per ton feed. In order to compare the impact of this yeast on the specific and non- specific immunity of infectious bursal disease (IBD) The titre of three types of commercial vaccines used in Syria against infectious bursal disease was estimated. The vaccines are two imported $(1,2)$ and a local one (3). The study has confirmed that there were clear significant variances $(\mathrm{P}<0.05)$ between the control and the experimental groups which added to its feed a yeast beer during all stages of breeding for the percentage of lymphocytes which were higher in treated groups than in the control ones.

Key words: دجاج اللحم ، المناعة ، خميرو البيرة (الجعة)

\section{INTRODUCTION}

\section{مقدمـة}

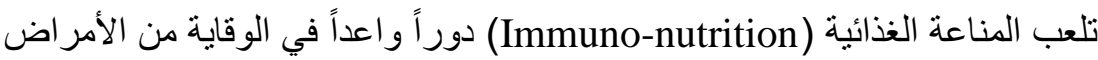

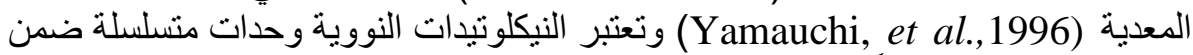
الخلايا و هي مهمة حيوياً لأداء وظائف العضويات الحئ الحية.

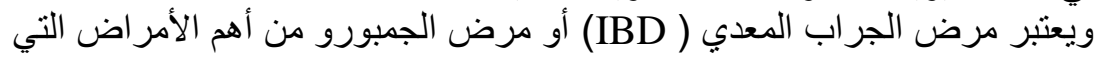

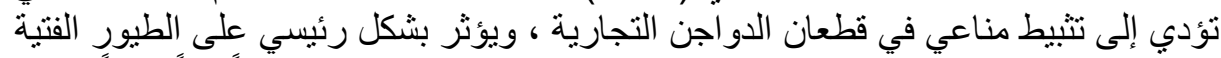

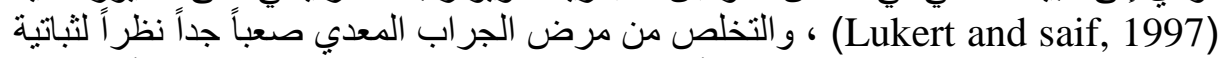

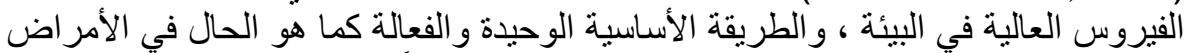

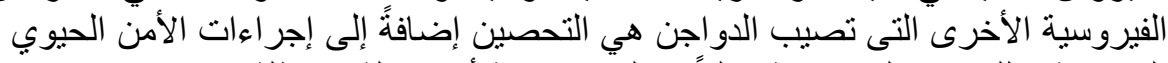
المعروفة واللقاحات المستخدمة حالياً إما لقأحات حية أو مقتولة التهن (معطلة).

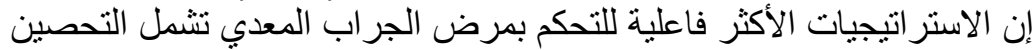

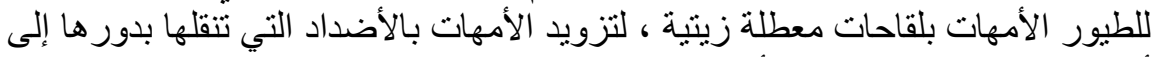

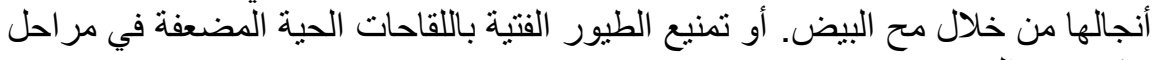

تصاحب بعض أنواع اللقاحات الحية حالة تثبيط مناعي عابر ، و التي يمكن أن تسبب مبكرة من العمر. آفات مشابهة للخمج الطبيعي عند الطيور الطياع المحصنة (Muller et al ., 2002).

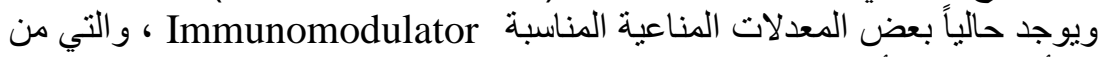

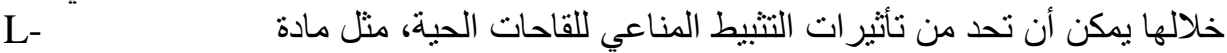
arginine

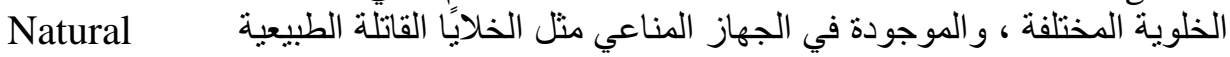

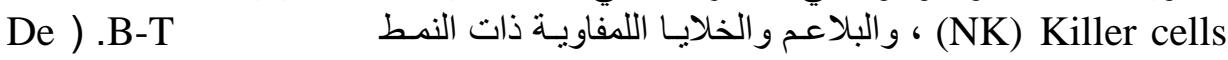
.(Jonge et al ., 2002 , Park et al.,1991 وحيث أن العديد من المُعدلات المناعية ذات النمط الور اثي الحئ الحيوي تؤدي إلى تحسين أداء الجهاز المناعي ، وخاصة تلك المعدلات المناعية ذات المنشأ النطبيعي والتي يتمثل 
تركيبها بالمستقبلات النيكلوتيدية النووية الطبيعية، و التي تتضمن البريميدات ومستقبلات

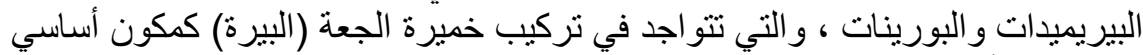

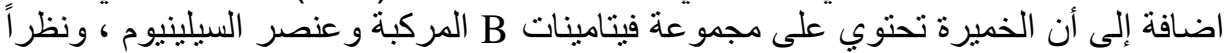

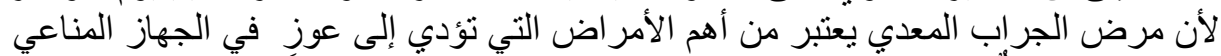

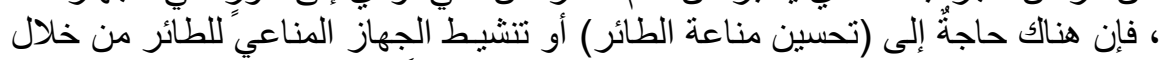

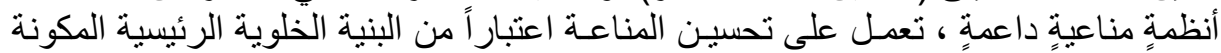

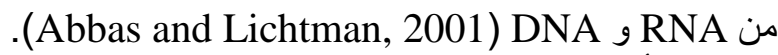

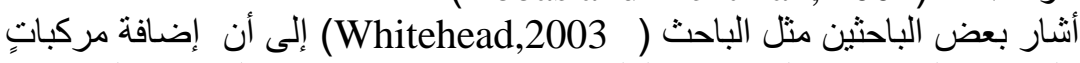

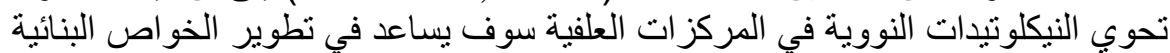
المعوية ، وبالتالي تحسين وظائف النّائ القناة المعوية.

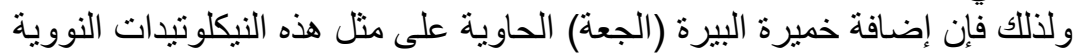

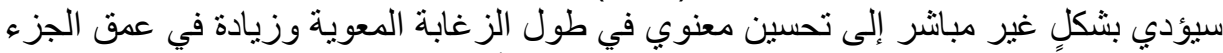

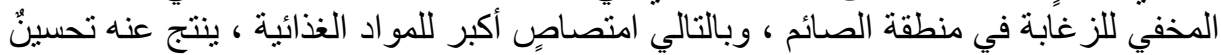

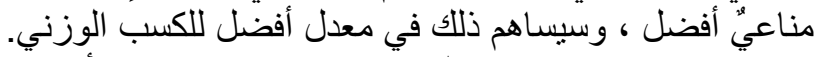

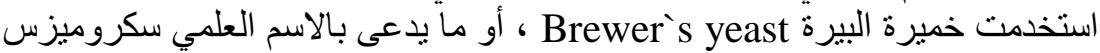

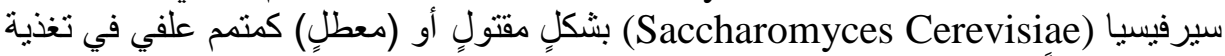

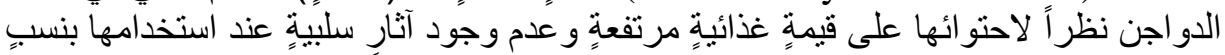

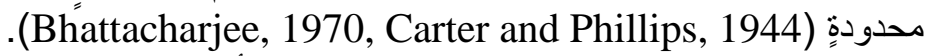

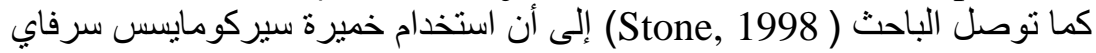

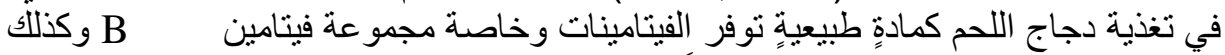

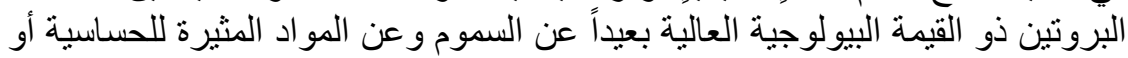
المركبات السرطانية عند استخدام مركبات صنعية غير طبيعية.

\section{MATERIALS and METHODS مواد وطرق العمل}

مواد العمل Materials:

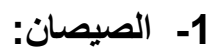

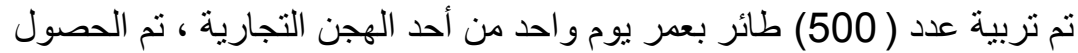

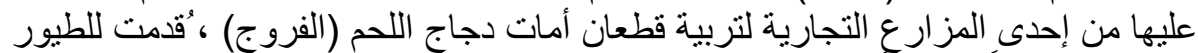

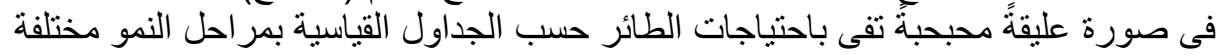

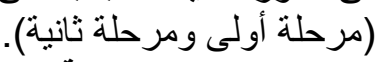
2- خميرة البيرة (الجعة):

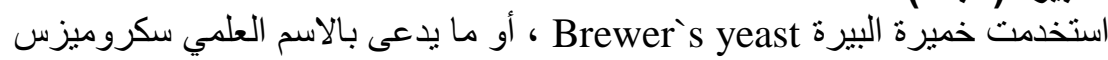

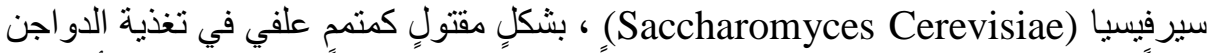

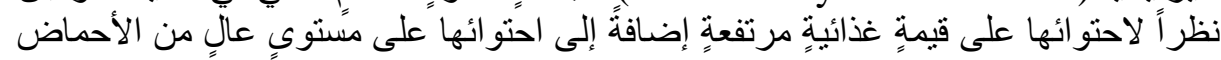

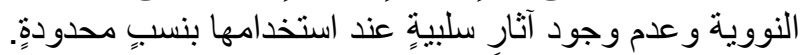

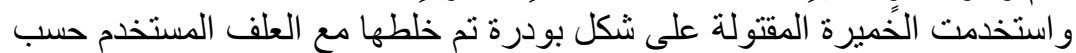

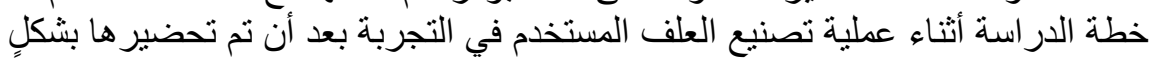
مقتولٍ من خلال تعريضهاء لبخار لمدة ( 4) ساعات مع الحفاظ على درجة الحر ارة ( 


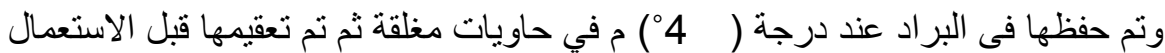

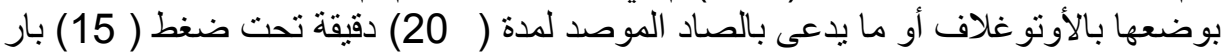

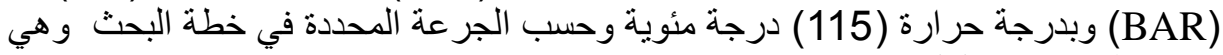
1000 غ غ اطن من العلف.

Methods: طرق العمل 1- مجاميع الاراسة :The Study Groups:

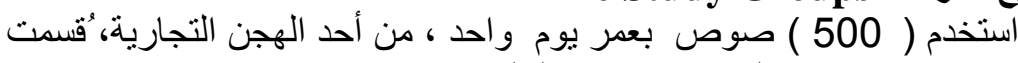
الطيور إلى عدة مجاميع مستقلة عن بعضها كالثنالي:

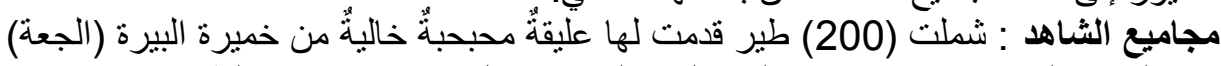

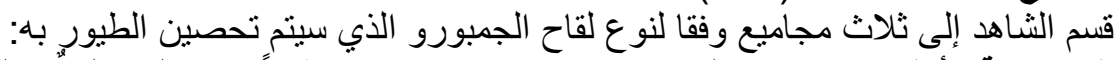

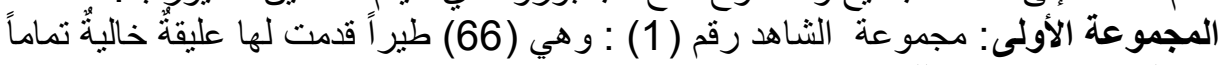

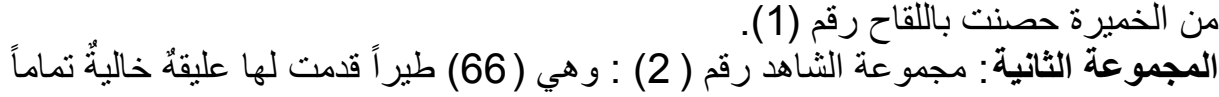

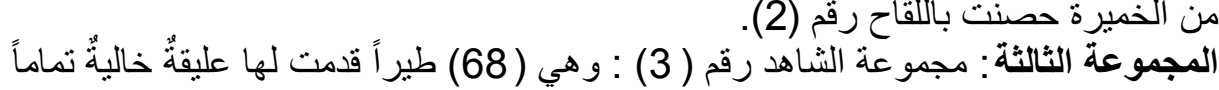

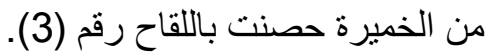

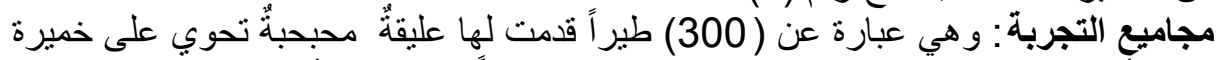

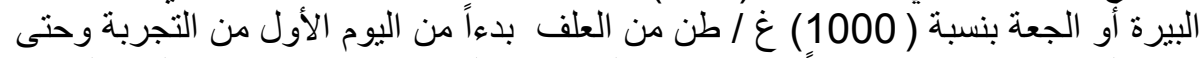

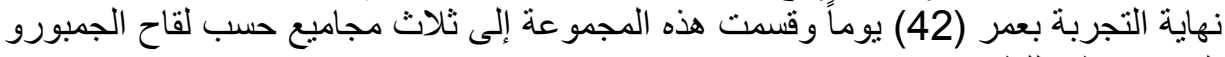
الذي سيعطى للطيور.

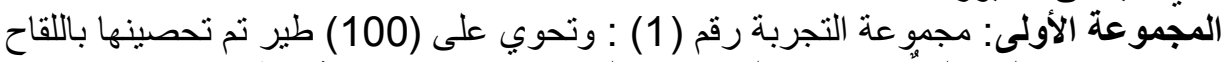

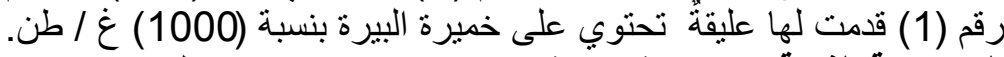

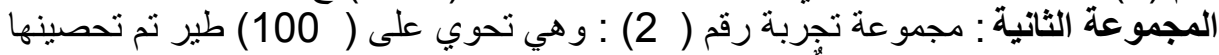

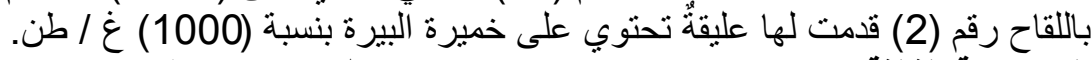

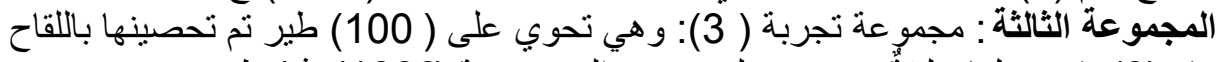

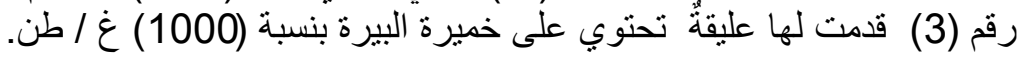

عينات الام Blood Samples

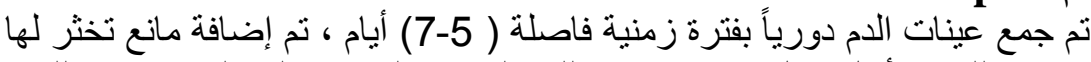

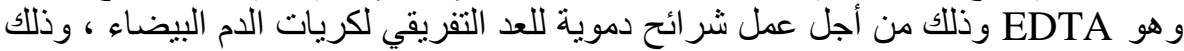

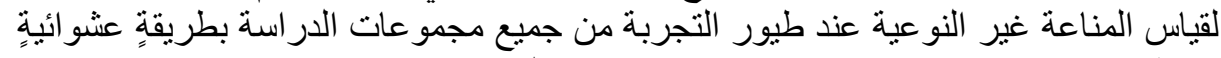

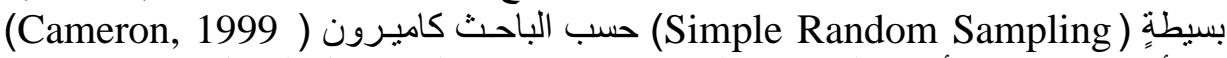

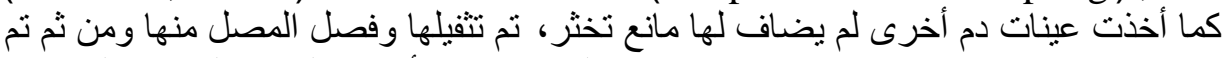

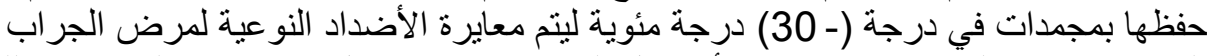

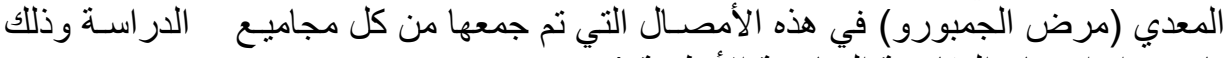

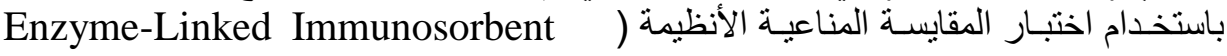
(ELISA) (Assay

: Serological Tests الاختبارات المصلية 


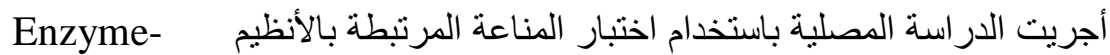

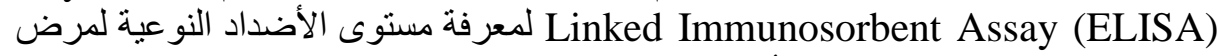
الجراب المعدي في مصل الدم ، وُيعد هذا الاختبار هو المفضل في عمليات التقصي المصني التصني

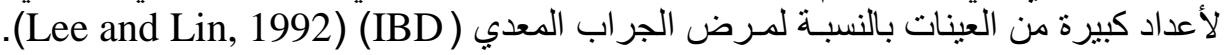

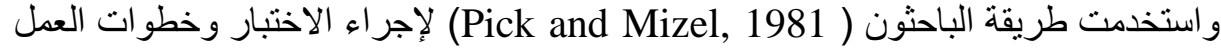
حسب توصيات الثركة المنتجة للمجمو عة التشخيصية.

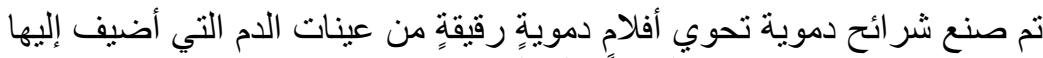

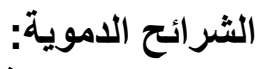

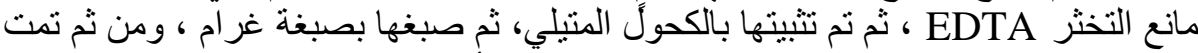

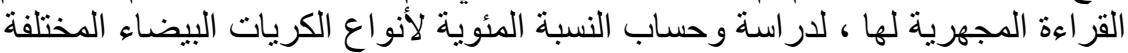

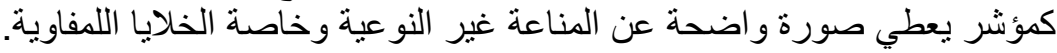

طريقة التحليل الإحصائي: Statistic Analysis Method درست الفروقات في معايير الأضداد بين مجا ميع الدراسة المختلفة باستخدام طريقة

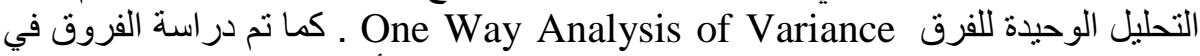

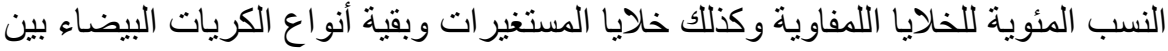

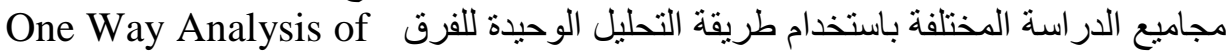
.Variance استخدم برنامج التحليل على الحاسوب (Statistix, 1998)، لإجر اء جميع التحاليل الإحصائية في هذه الدراسة.

\section{RESULTS}

\section{النتائسج}

1- تأثير خميرة البيرة (الجعة) على المناعة النوعية: Impact of Brewer`s yeast on the Specific Immunity مقارنة معايير الأضداد باستخدام طريقة التحليل الوحيدة للفرق

\section{:One-Way-Analysis of Variance}

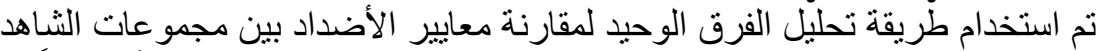

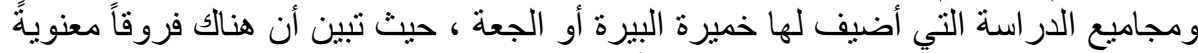

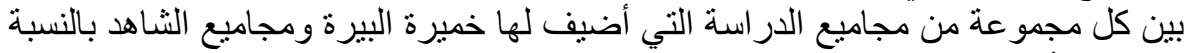
0. ) $\mathrm{p}=$

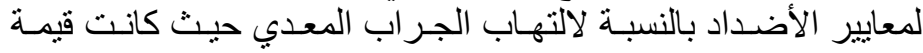
. (P<0.05) (0008

يوضح الجدول رقم ( 1) مقارنة معايير الأضداد لمرض التهاب الجراب المعدي باستخدام

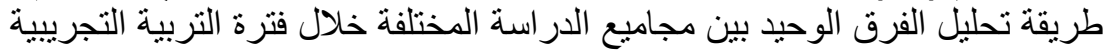

\begin{tabular}{|c|c|c|c|c|c|c|}
\hline تجربة 3 & شـاهد 3 & تجربة2 & شاهد 2 & تجربة 1 & شاهد 1 & الطيور \\
\hline 3322.7 & 3322.7 & 3322.7 & 3322.7 & 3322.7 & 3322.7 & 5 يوم \\
\hline
\end{tabular}




\begin{tabular}{|c|c|c|c|c|c|c|}
\hline 3928 & 3446.4 & 3928 & 3446.4 & 3928 & 3446.4 & 13 يوم \\
\hline 4559.8 & 3585 & 4182.8 & 3626.6 & 4086.2 & 3471.4 & 22بوم \\
\hline 5540.2 & 5188.6 & 4798.3 & 3654.3 & 5445.7 & 3791.7 & 29 يوم \\
\hline 8504.2 & 5765.7 & 6561.6 & 6458.9 & 7950.4 & 6491 & 36 يوم \\
\hline 15662 & 12865 & 15152 & 12023 & 15528 & 12584 & 41 يوم \\
\hline
\end{tabular}

$(\mathrm{P}=0.0008<0.05)$

المخطط البياني (1) مقارنة معايير الأضداد لمرض التهاب الجراب المعدي باستخدام طريقة

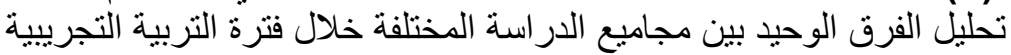

2- تأثير خميرة البيرة (الجعة) على المناعة غير النوعية: Impact of Brewer`s yeast on non-Specific Immunity مقارنة النسب المئوية للخلايا اللمفاوية والمستغيرات باستخدام طريقة التحليل الوحيدة للفرق One-Way-Analysis of Variance: تم استخدام طريقة التحليل الوحيدة للفرق بين مجاميع الثاهد و التي لم يزود التير غذائها

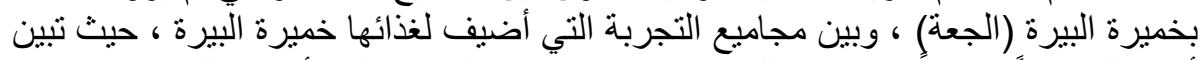

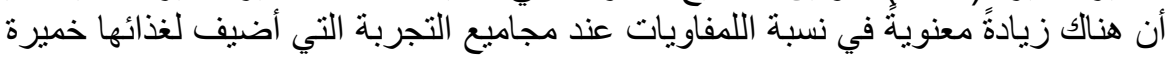




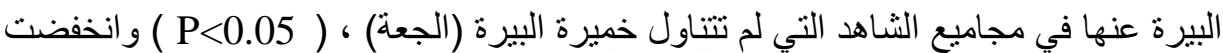
بالمقابل نسبة خلايا المستغير ات انخفاضاً معنوياً عند مجاميع الدر اسة (P<0.05)

الجدول رقم (2) مقارنة النسب المئوية للخلايا اللمفاوية بين مجاميع الدراسة المختلفة خلال فترة التربية التجريبية

\begin{tabular}{|c|c|c|c|c|c|c|}
\hline التجربة 3 & الثـاهد 3 & التجربة 2 & الشـاهد 2 & التجربة 1 & الشـاهد 1 & \\
\hline 35.2 & 33.6 & 34.1 & 33.7 & 31.9 & 30.2 & عمر الطيور 7 يوم \\
\hline 37.5 & 35.5 & 36.4 & 34.7 & 35.3 & 34.4 & عمر الطيور 14 يوم \\
\hline 45.3 & 43.3 & 44.2 & 43.1 & 43.8 & 42.7 & عمر الطيور 21 يوم \\
\hline 49 & 46 & 48.2 & 47.1 & 47.8 & 46.5 & عمر الطيور 28 يوم \\
\hline 60 & 55 & 58 & 55.2 & 57.2 & 56.4 & عمر الطيور 35 يوم \\
\hline 63 & 50 & 62.2 & 59.9 & 61.2 & 59 & عمر الطيور 42 يوم \\
\hline
\end{tabular}

المخطط البياني رقم (2) مقارنة النسب المئوية للخلايا اللمفاوية بين مجاميع الدراسة المختلفة خلال فترة التربية التجريبية

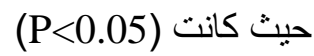
الجدول رقم (3) مقارنة النسب المئوية لخلايا المستغيرات بين مجاميع الدراسة المختلفة خلال فترة التربية التجريبية

\begin{tabular}{|c|c|c|c|c|c|c|}
\hline التجربة 3 & الثاهد 3 & التجربة 2 & الثاهد 2 & التجربة 1 & الثشاهد 1 & \\
\hline 50.6 & 52.8 & 51.9 & 53.3 & 51.1 & 52.4 & عمر الطيور 7 \\
\hline 47.7 & 48.7 & 47.6 & 47.9 & 49.9 & 48.6 & عمر الطيور 14 \\
\hline
\end{tabular}


Assiut Vet. Med. J. Vol. 56 No. 126 July 2010

\begin{tabular}{|c|c|c|c|c|c|c|}
\hline 37.7 & 38.7 & 37.5 & 39.1 & 37.9 & 38.2 & عمر الطيور 21 يوم \\
\hline 32 & 34 & 33.8 & 34.2 & 33.5 & 34.5 & عمر الطيور 28 \\
\hline 23 & 25 & 24 & 24.5 & 23.8 & 24.3 & عمر الطيور 35 \\
\hline 22 & 23 & 22.6 & 22.8 & 21.5 & 22.4 & عمر الطيور 42 \\
\hline
\end{tabular}

المخطط البياني رقم ( 3) مقارنة النسب المئوية لخلايا المستغير ات بين مجاميع الدراسة المختلفة خلال فترة التربية التجريبية

\section{DISCUSSION}

حيث كانت

\section{المناقشـة}

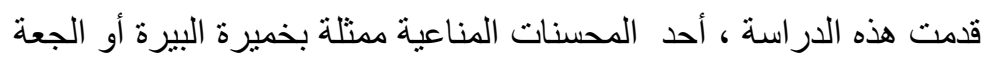

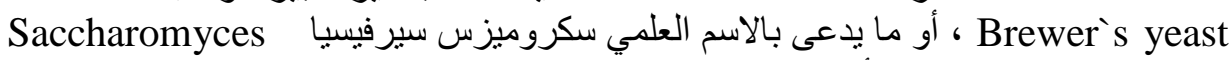

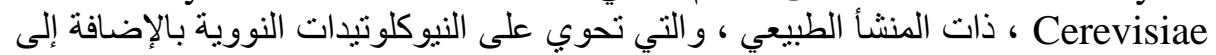

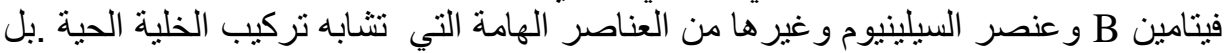

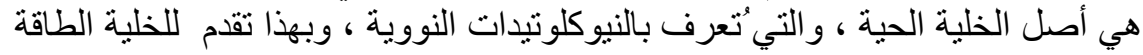


اللازمة لعملية الانقسام الخلوي مباثرة بالإضافة إلى المواد الهامة في بناء الخلية ، و هذا يؤدي

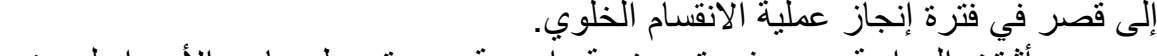

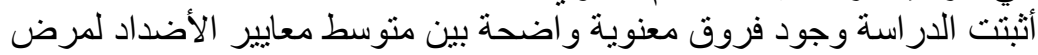

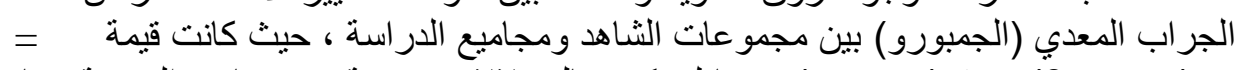

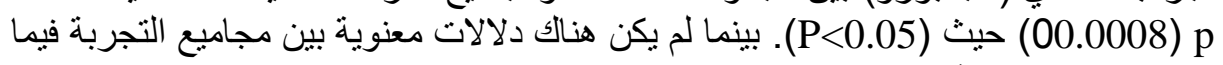

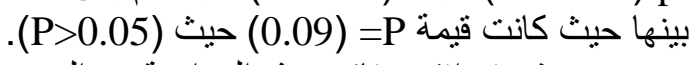

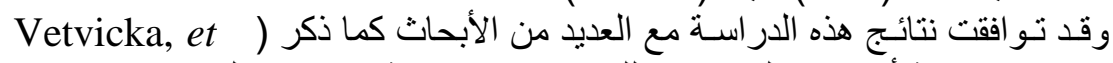


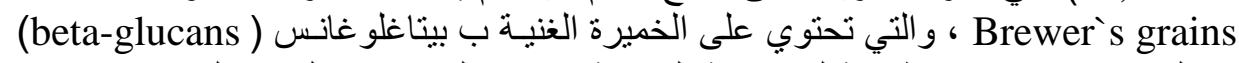

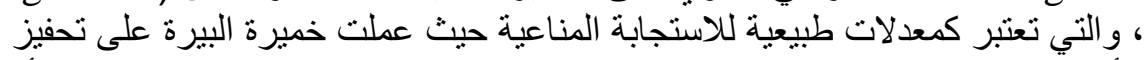

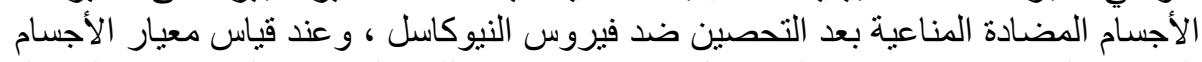

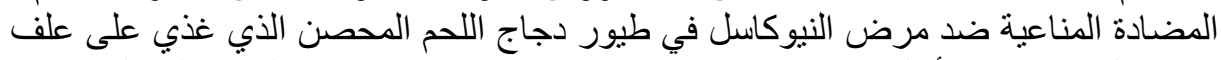

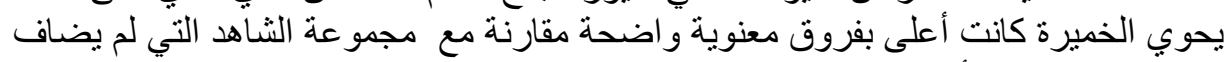

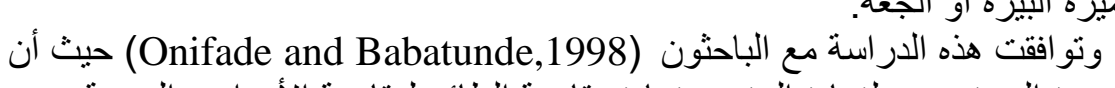

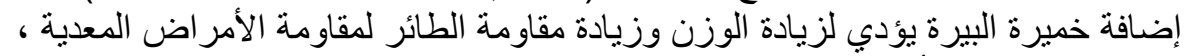

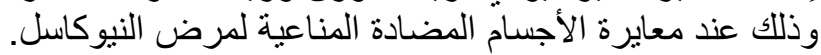

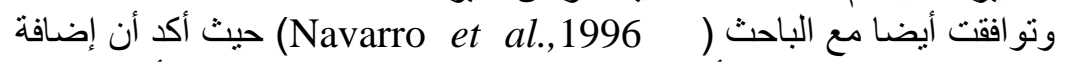

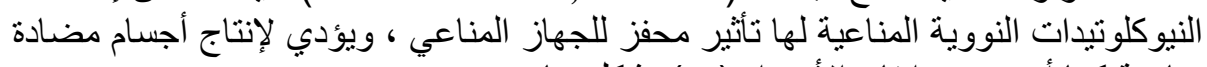

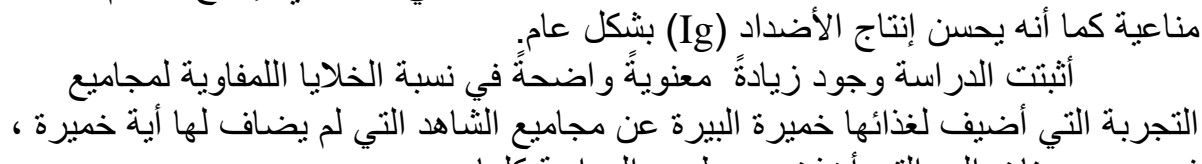
في جميع عينات الدم التي أخذت من طيور البيرة الدراسة كلها.

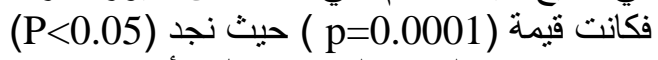

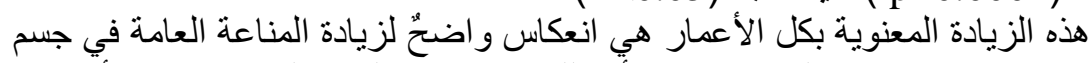

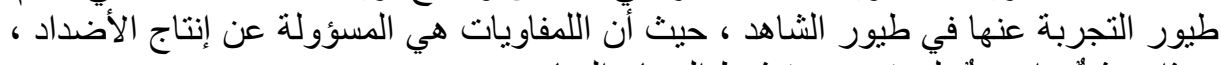

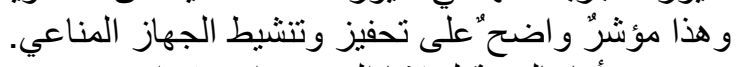

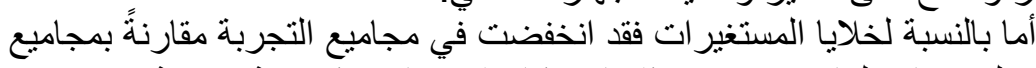

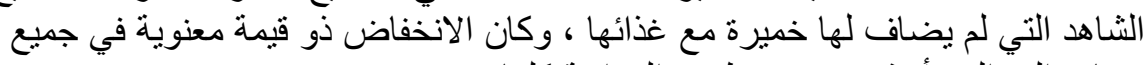

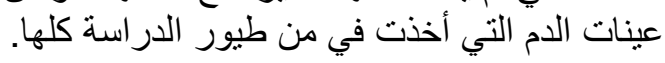

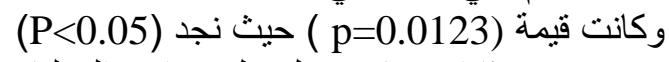

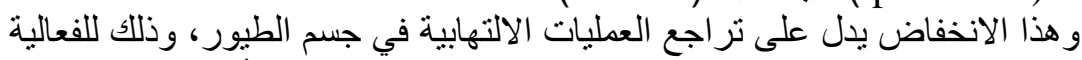

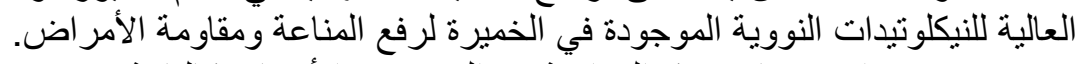

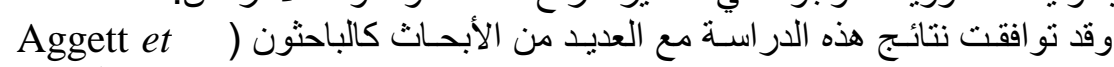
(al., 2002, Adjei et al., 1993 النيوكليوتيدات النووية كمنممات علفية يمكن أن يحرض ويحسن المناعة الخلوية

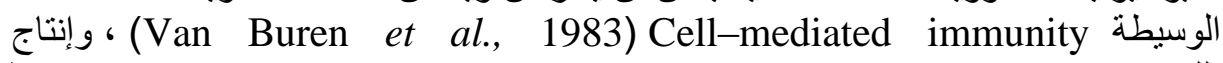

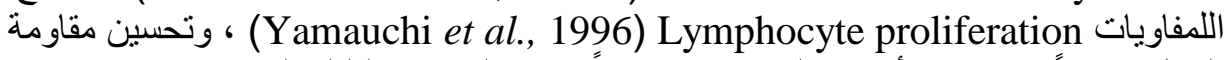

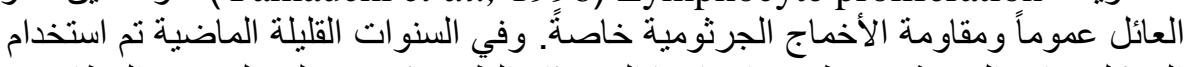

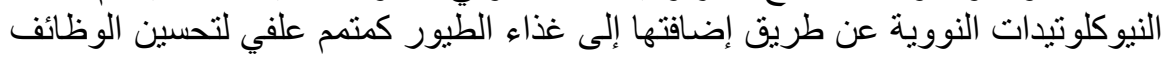




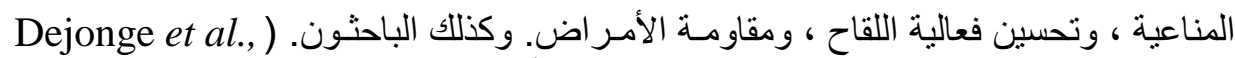

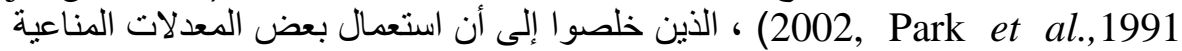

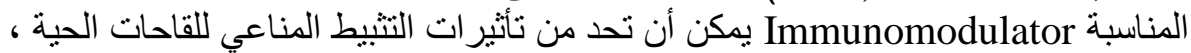

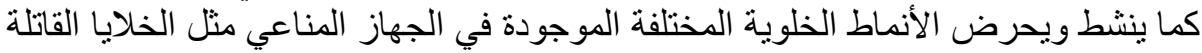

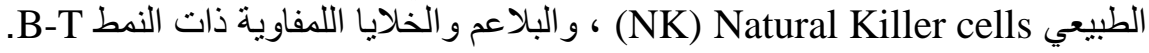

\section{CONCLUSION الاستنتاج}

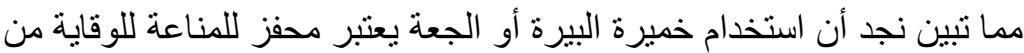

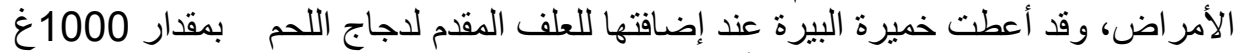

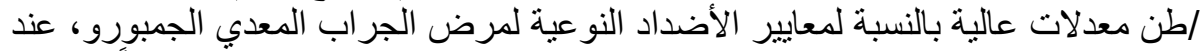

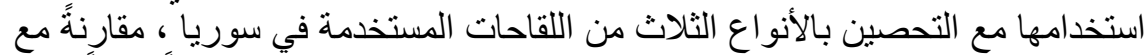

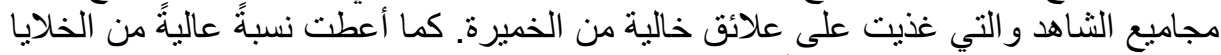

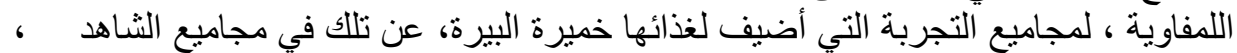

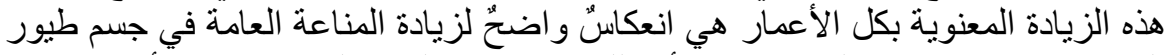

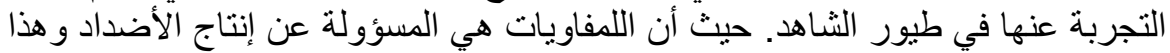
مؤشرٌ و اضح على على طحفيز وتنشيط الجهاز المناعي.

\section{REFERENCES}

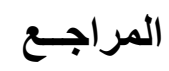

Abbas, A.K. and A.H. Lichtman (2001): Basic Immunology: Functions and Disorders of the Immune System. Philadelphia: W.B. Saunders Co., pp 28-61.

Aggett, R.; Leach, J.L.; Rueda, R. and Maclean, W.C. (2002): Innovation in Infant Formula Development: A Reassessment of Rib nucleotides. Nutrition Journal, 19: 375-84.

Adjei, A.A.; Takamine, F.; Yokoyama, H.; Shiokawa, K.; Matsumoto, Y. and Asto, L. (1993): The effects of oral RNA and intraperitoneal nucleoside- nucleotide administration on methillin- resistant Staphylococcus aureus Infection in mice. Journal of Parenter Enteral Nutrition. 17: 148-52.

Bhattacharjee, J.K. (1970): Microorganisms as potential sources of Food, Advan. Appl. Microbiol., 13: 139-161.

Carter, H.E. and Phillips, G.E. (1944): Nutritive value of yeast protein. Federation Proe., 3: 123-128.

Cameron, A. (1999): Survey Toolbox A Practical Manual and Software Package for Active Surveillance of Livestock Diseases in 
Developing Countries. Australian Centre for International Agricultural Research Monograph No. 54. pp 37-47.

De Jonge, WJ.; Kwikkers, WL.; TeVelde, AA.; Van Deventer, SJ.; Notlte, MA. and Mebius, RE. et al. (2002): Arginine deficiency affects early B cell maturation and lymphoid orgqn development in transgenic mice. J Clin Invest,110 (10): 1539-48.

Lukert, P.D. and Saif, Y.M. (1997): Infectious bursal disease in: B.W. Calnek, H.J. Barnes, C.W. Beard, L.R. McDouglad, Y.M. Saif (Eds)., Diseases of Poultry, $10^{\text {th }}$ ed, lowa State University Press, Ames, IA, PP. 721-738.

Lee, L.H. and Lin, Y.P. (1992): Amonoclonal antibody capture enzyme linked Immunosorbent assay for detecting antibodies to infectious bursal disease virus. Journal of Virological Methods, 36: 13-23.

Muller, H.; Islam, R. and Raue, R. (2002): Research on infectious bursal diseas the paste, the present and the future.Veterinary Microbiology Journal, 97: 153-165.

Navarro, J.; Ruiz-Bravo, A.; Jimenez-Varela, M. and Gil, A. (1996): Modulation of antibody-forming cell and mitogen-drive lymphoproliferative responses by die- tarynucleotides in mice. Immunology Letters 53: 141-145.

Onifade, A.A. and Babatunde, G.M. (1998): Comparisonthe utilization of palm kernel meal, brewers' driedgrains and maize offal by broiler chicks. Br. Poult.Sci., 39: 245-250.

Park, KG.; Hayes, PD.; Garlick, PJ.; Sewell, H. and Eremin, O. (1991): Stimulation of lymphocyte natural cytotoxicity by L-arginine. Lancet. 16. 337(8742): 645

Pick, E. and Mizel, D. (1981): Rapid microassays for the measurement of superoxide and hydrogen peroxidase production by macrophages in culture using an automatic immunoassay reader. Journal of Immunol. Methods, 46: 211-26.

Stone, C. (1998): Yeast products in the feed industry. Ed. By Mills, d. Inc. Cedar Rapids, Iowa., p. 10-11.

Statistix, (1998): Analytical Softewar, Guideline manual, Version, 2.0. USA.

Van Buren, C.T.; Klkararni, A.D.; Schandle, V.B. and Rudolph, F.B. (1983): The Influence of dietary nucleotides on cell-mediated immunity. Transplantation Journal, 36: 350-2. 
Vetvicka, V.; Thornton, B.P. and Ross, G.D. (1996): Soluble beta-glucan polysaccharide binding to the lectin of neutrophil or natural killer cell complement receptor type 3 (CD11b/CD18) generates a primed state of the receptor capable of mediating cytotoxicity of iC3b-opsonized target cells. J. Clin Invest. 1996; 98(1): 50-61. doi: 10.1172/JCI118777.

Whitehead, J.A. (2003): Effect of Ascogen on intestinal morphology and the performance of the broiler chicken. University of Nottingham, UK.

Yamauchi, K.; Adjei, A.A.; Ameho, C.K.; Chan, Y.C. and Kulkarni, A.D. Sata. (1996): A nucleoside-nucleotide mixture and its components increase lymph proliferative and delayed hypersensitivity responses in mice. Journal of Natural, 126: 1571-7. 